\title{
Small system modelling of real wages, inflation, unemployment and output per capita in Italy 1970-1994.
}

\author{
Massimiliano Marcellino \\ Istituto di Economia Politica, \\ and \\ IGIER \\ Bocconi University, Milan, Italy.
}

\author{
Grayham E. Mizon* \\ Economics Department, \\ Southampton University, \\ UK.
}

First version June 1997. This version October 2000.

\begin{abstract}
The relationships between real wages, output per capita, inflation and unemployment in Italy between 1970 and 1994, are modelled using a cointegrated vector autoregression. There is evidence of a change in the underlying equilibria and in the dynamic evolution of the variables, probably associated with the substantial changes in many sectors of the Italian economy after 1979. Alternative ways to model structural change in the Italian labour market are considered. In adopting a split sample approach the results favour an hysteresis interpretation of unemployment.
\end{abstract}

${ }^{*}$ This work was done as a part of the Phare ACE Project (P95-2145-R) Inflation and Unemployment in Economies in Transition, funded by the European Commission, and the authors thank the other participants in the project for their comments. Three anonymous referees and seminar participants at the Australian National University, University of Melbourne, and University of Southampton are thanked for their valuable comments. Helpful comments were provided by discussants Clara Jorgenson and Hanne Lyngesen at the conference on European Unemployment and Wage Determination held at the EUI in June 1998. It is also a pleasure to acknowledge the constructive comments on the paper made by David Hendry. Mizon is grateful for financial support from the EUI Research Council and the UK Economic and Social Research Council under grant L116251015. 


\section{Introduction}

Sargan (1964) sowed the seeds for many important changes in the practice of econometrics, especially in the analysis of macroeconomic time series. In this seminal paper, in addition to demonstrating empirically how important 'real-wage resistance' is in wage bargains, so that there exists a 'catch-up' mechanism for recouping losses incurred from unanticipated inflation, Denis Sargan formulated and used a new class of dynamic econometric model that is now known as the 'error correction model' and plays a pivotal role in cointegration analysis. It gives us much pleasure therefore to contribute to this Special Issue of the Journal of Applied Econometrics in his honour a study of the relationship between real wages, output per capita, inflation, and unemployment using a vector equilibrium correction model ( $\left.\mathrm{VE}_{q} \mathrm{CM}\right)$.

For many years after 1945 western European economies were able to maintain high rates of employment and modest rates of inflation. However, by the 1970s historically high rates of inflation were being experienced, although unemployment rates were still low. This led numerous European countries in the early 1980s to switch the emphasis from high employment Keynesian-type policies to tight monetary policies to combat the bogey of inflation. Hence in very broad terms there was a change in priorities (from maintaining 'full' employment to stabilizing the rate of inflation at a 'low' level), with a consequent switch in the type of economic policies adopted. Therefore econometric modelling of wages, prices, unemployment and output per capita for these economies may well encounter difficulties associated with structural changes, unless the underlying changes in economic priorities and policies are accounted for in the models. This paper develops models of the determination of wages and prices in the Italian economy, which although having a number of common features with other European countries, has been characterized by several particular features (such as wage indexation via 'la scala mobile'), and since the late 1970s the whole economy has experienced many changes.

In view of the non-stationary nature of the data being modelled, and the desire to embed the modelling of real wages in a small system containing some of the macro variables relevant to wage determination, the general class of model adopted is the cointegrated VAR (vector autoregression). Once the number of cointegrating vectors has been determined the VAR is re-parameterized as a $\operatorname{VE} q \mathrm{CM}$ (see Hendry, 1995 and Mizon, 1995). In addition to capturing changes in the short run dynamics of the system and allowing for the effects of autonomous shifts via event-specific dummy variables, attention is paid to changes in the equilibria of the system. In fact, there is evidence of structural change having taken place around 1980. Consequently, forecasting the events of the 1980s and 1990s using a 1970s-based VE $q$ CM model will be extremely difficult (see inter alia Clements and Hendry, 1999, and Mizon, 1995). Whilst forecasting the later period can be done successfully using a VAR in the first or second differences of variables (denoted DVAR and DDVAR respectively), such models are less valuable for conducting economic policy analysis which usually analyzes partial responses between the levels of variables, not their changes. Banerjee, Hendry and Mizon (1996), Hendry and Mizon (2000), and Hendry and Mizon (1998) present a more detailed discussion of these issues.

Section 2 provides a description of the major features of the sample data that are modelled in the later sections, and briefly reviews the literature which has previously analyzed this sector of the Italian 
economy. The class of statistical model used is described in Section 3. Sections 4 and 5 contain splitsample analyses of a system for real wages, inflation, output per capita and unemployment for the 1970s, and the 1980s and 1990s, respectively. Section 6 contains analysis of possible homogeneity across the whole sample period using various tests for parameter constancy and forecast accuracy, and discusses the alternative of analyzing an open system that conditions on other macroeconomic variables. Conclusions are presented in Section 7. Details of the definitions and sources of the data are given in a Data Appendix.

\section{The Sample Data and Historical Perspective}

The sample data are quarterly seasonally adjusted for the period 1970(1) to 1994(4). $w_{t}$ is the log of nominal average earnings which is referred to as wages, $p_{t}$ is the log of the consumer price index, so that $(w-p)_{t}$ is the log of real wages and $\Delta p_{t}$ is the quarterly inflation rate. $u_{t}$ is the log of the percentage unemployment rate. $(y-l)_{t}$ is the log of the ratio of real GDP to total employment which was used in Sargan (1964) as a simple measure of productivity, though as discussed below this variable is closely related to log labour share and a measure of the output gap. For further details see the Data Appendix.

Figure 1 contains full sample time plots of the main variables $(w-p)_{t},(y-l){ }_{t}, u_{t}, \Delta p_{t}$ and their first differences.
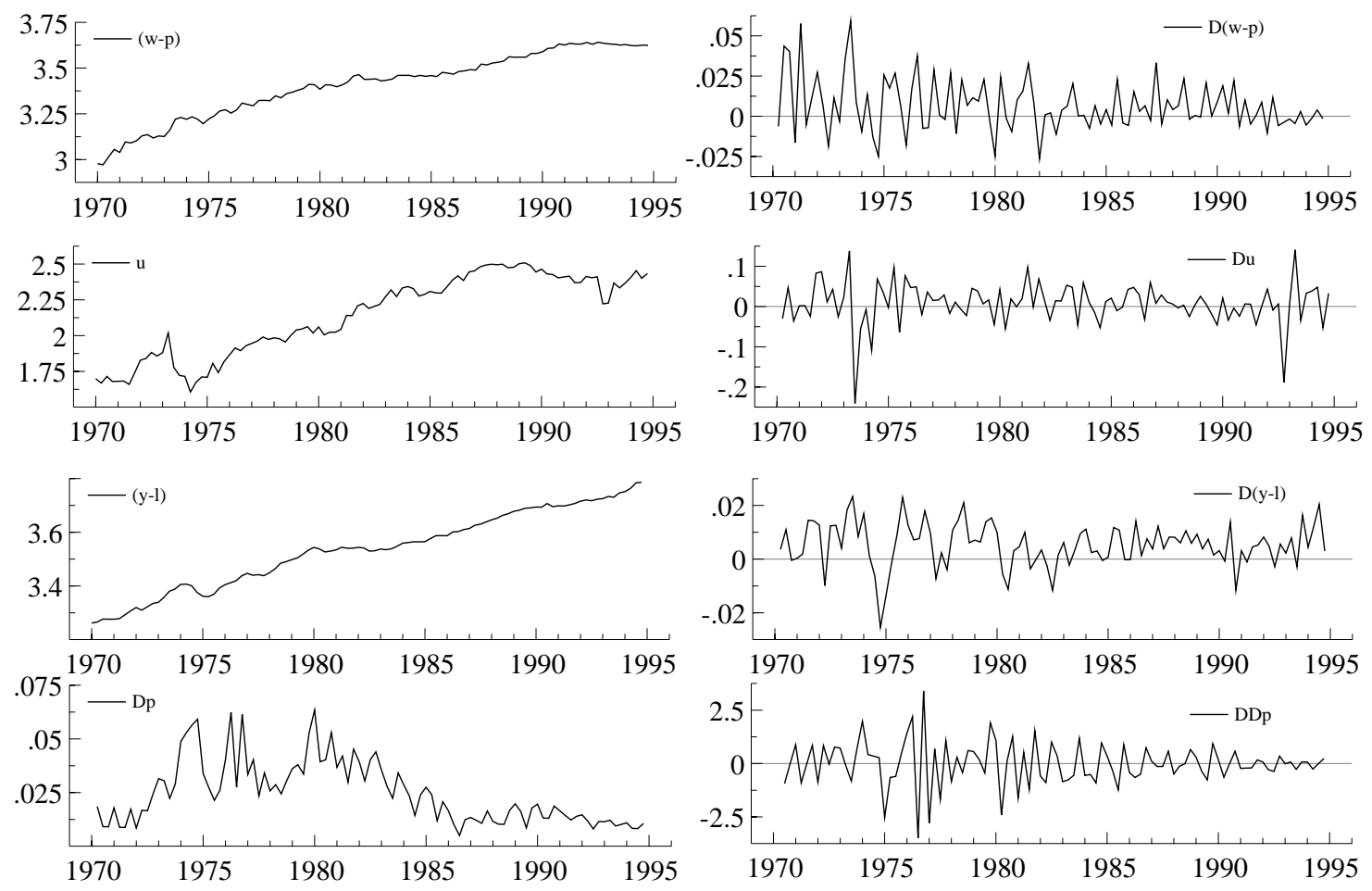

Figure 1 Full sample levels and first differences.

Although $(w-p)_{t}, u_{t}$ and $(y-l)_{t}$ appear to be dominated by positive trends, the dominant path of

\footnotetext{
${ }^{1}$ We are grateful to Roberto Golinelli for kindly providing most of these data. Seasonally unadjusted data are not available for all the chosen variables over this period.
} 
$\Delta p_{t}$ rises strongly from 1972 to 1980 whereupon it falls to 1986, and then remains constant to the end of the sample. $\Delta^{2} p_{t}, \Delta(w-p)_{t}$ and $\Delta(y-l)_{t}$ reveal greater variability in the earlier part of the sample. $\Delta u_{t}$ on the other hand behaves differently, having fairly constant variability throughout the sample, the exceptions being two very short periods of high variability in 1973 and 1992. The correlograms (not presented) of $(w-p)_{t}$ and $(y-l){ }_{t}$ indicate nonstationarity for the full sample and split samples with the break at the end of 1979. However, the correlograms for $\Delta p_{t}$ and $u_{t}$ exhibit different characteristics in each of the periods 1970-1994, 1970-1979 and 1980-94. This evidence already indicates that there may have been a structural change around the beginning of the 1980s. Hence it is important to consider some of the relevant economic history for Italy and refer to other studies that have analyzed similar data sets.

Unemployment in Europe started rising in the late 1970s and has been one of the most serious social and economic problems for many members of the European Union, see for example Alogoskoufis, Bean, Bertola, Dolado and Saint-Paul (1995). Italy is particularly affected by this problem, as the time plot of the log of unemployment $\left(u_{t}\right)$ in figure 1 testifies. One of the sharp changes in unemployment noted above (up to 8\%) came in 1973(2) just prior to the first oil crisis, and coincided with a lira devaluation. Between 1973 and 1975 the rate of unemployment fell to 6\%, the rate that had prevailed for many years previously. However, from 1975 the unemployment rate rose steadily, reaching 8\% by 1980, and further peaks of more than $12 \%$ (which corresponds to nearly 3 million unemployed people) in the period 1986-1988. Although there were reductions afterwards, it never fell below 10\%. The available statistics though require careful use. For example, the big fall in the final quarter of 1992 (the second of the big changes noted above) is almost certainly the consequence of a major change in the questionnaire used to collect the labour market data, so that the data pre and post 1992(3) are not comparable - this issue is discussed further in Section 5.

Figure 2 shows evidence of changing relationships between $(w-p)_{t}$ and $u_{t}$, and between $\Delta p_{t}$ and $u_{t}$. It is instructive therefore to consider the major supply and demand shocks that affected the Italian economy in the 1970s, 1980s, and 1990s - as done by Bean (1994a), Bean (1994b), and Alogoskoufis et al. (1995). The 1970s were dominated by the two oil crises, and by major increases in the price of raw materials more generally. These led to a rapid increase in the aggregate inflation rate - see the quarterly inflation rate $\Delta p_{t}$ in figure 1. It is also evident from figure 2 that the relationship between $u_{t}$ and $\Delta p_{t}$ is quite different in the 1970s and in the 1980s and 1990s. In the first decade the two variables exhibit modest positive correlation $(+0.21)$, which is typical in periods of stagflation. In the second period the correlation is negative $(-0.79)$, which is more in line with a traditional Phillips curve-type relationship. However, these are bivariate descriptions ignoring the effects of other potentially relevant variables, and the sequential regression lines in figure 2 indicate substantial variability in the plot of $\Delta p_{t}$ against $u_{t}$.

The 1980s began with a period of strong disinflation, which was achieved by means of a restrictive monetary policy. Figure 3 highlights this in the sharp fall in inverse velocity of money $(m 2-p-y)$ in 1980 following the big increase in the interest rate $(R)$. Note that prior to the adoption of a tight monetary policy in 1980 the real interest rate $($ Real $R$ ) had been negative for many quarters. This restrictive policy,

\footnotetext{
${ }^{2}$ In the last two graphs $\Delta p$ and $u$ are scaled to have matching means and ranges.
} 

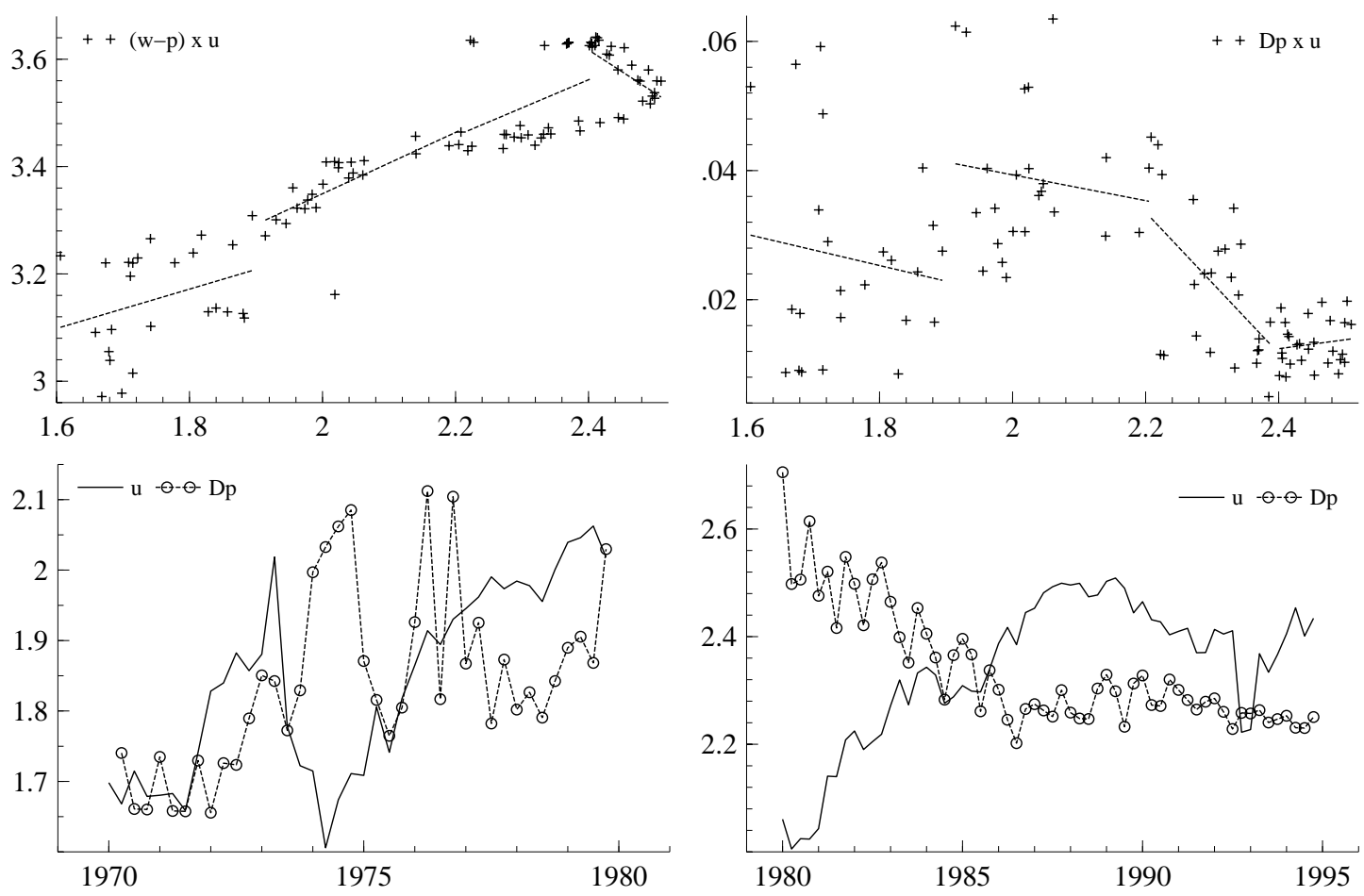

Figure 2 Real wages, inflation and unemployment.

together with the stagnation of world demand, brought the economy into the descending phase of the cycle after the peak in 1980(1).
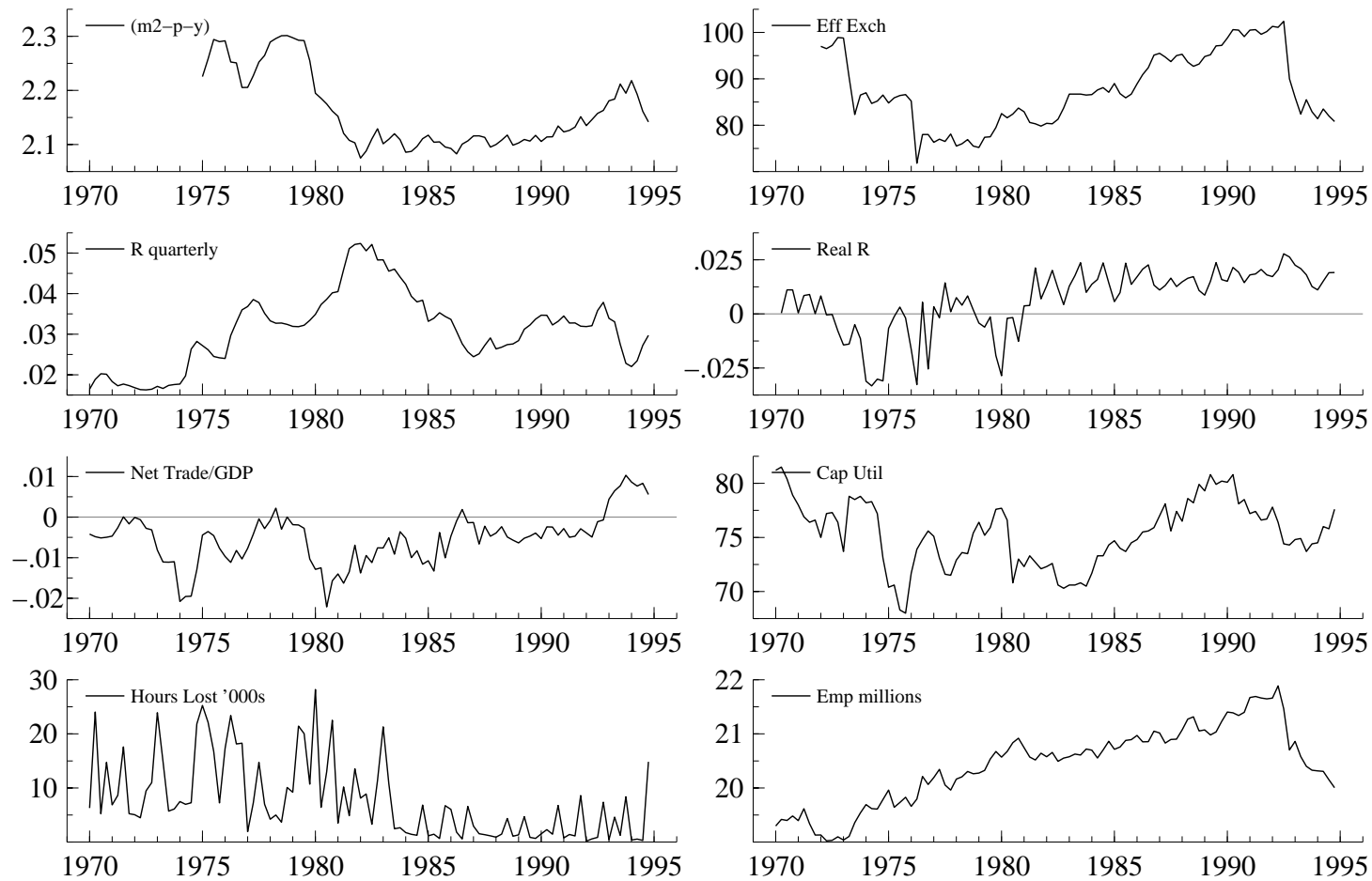

Figure 3 Money, employment, and trade variables. 

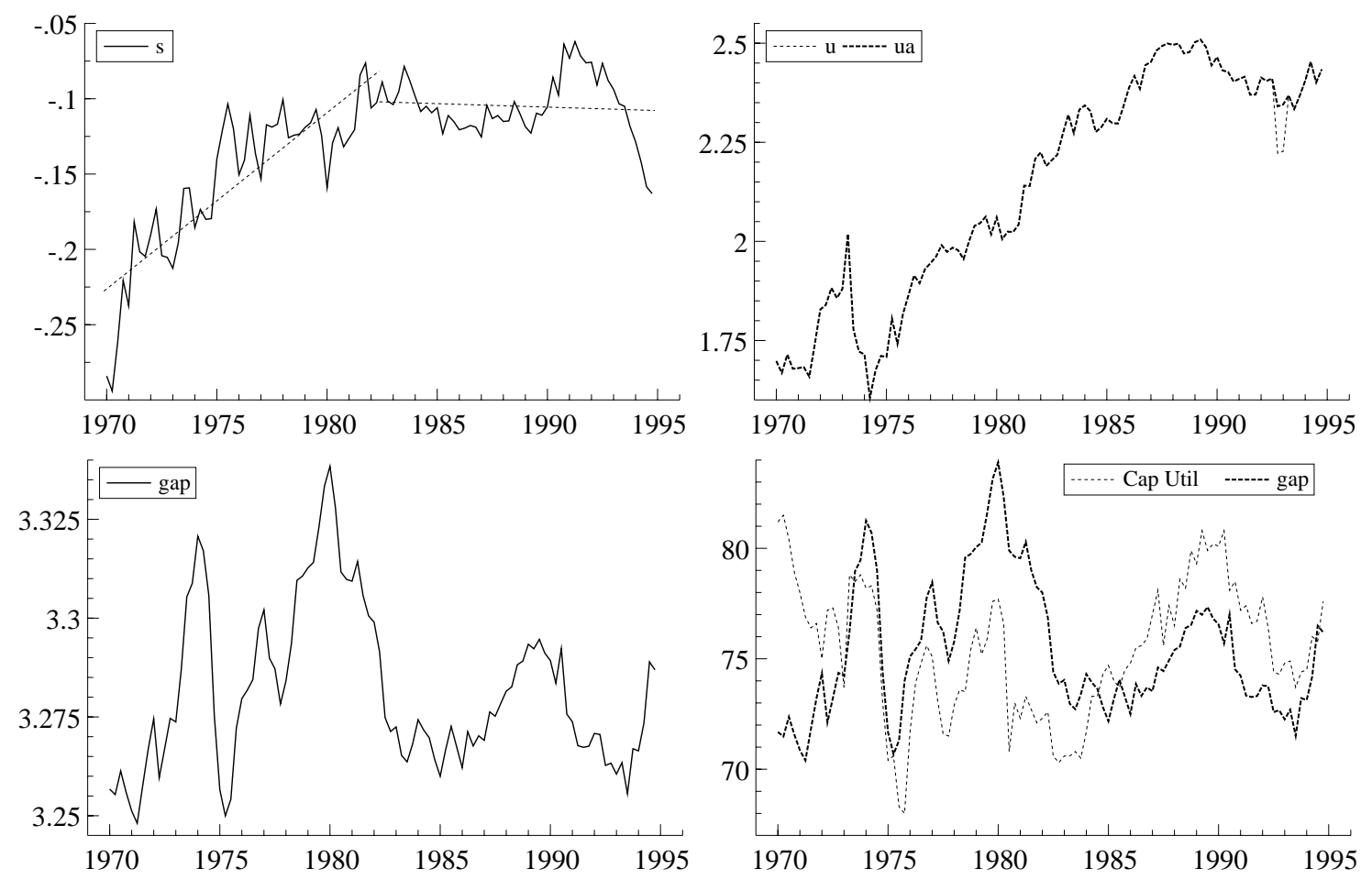

Figure 4 Labour share, adjusted unemployment, and output gap.

The behaviour of the lira exchange rate and the balance of payments was also rather different in the 1970s and the 1980s - see figure 3. In fact, there were big depreciations of the lira in 1973(2) and 1976(2), and other marked but less strong devaluations throughout the 1980s, culminating in the expulsion from the EMS in September 1992. The net trade balance relative to GDP (NetTrade/GDP) had a marked increase in volatility from 1980 onwards. The strong improvement in Net Trade/GDP at the end of the sample is mainly due to the real exchange rate depreciation. The tight monetary policy introduced at the time of the temporary exit from the EMS in September 1992 (Italy rejoined the EMS in November 1996), resulted in a dramatic fall in GDP and an even larger percentage fall in employment so that output per capita continued to grow.

A reform of the indexation law 'la scala mobile', which was introduced in 1975 to automatically increase wages in line with inflation, began in 1982. The average degree of coverage was gradually reduced, while after an agreement in 1992 the automatic indexation was abolished - see e.g. Erickson and Ichino (1994), Bertola and Ichino (1995) and the references therein for further details. Another possible explanation for the different labour market behaviour pre and post 1980 is the decline in union power during the later period, which can be proxied by the decrease both in working hours lost in labour disputes (Hours Lost in figure 3) and in union penetration measured by the fraction of eligible employees who become union members (see Bertola and Ichino, 1995). However, throughout most of the sample period Italian labour law has provided enormous security of tenure for employed labour, and so union membership in Italy is not as good an indicator of bargaining strength as it is in other countries such as the UK. Figure 3 also shows that capacity utilization (Cap Util) declined in the early 1970s, 
1980s and 1990s when there were recessions, but cross plots (not shown) of Cap Util with $u_{t}, \Delta y_{t}$, and Hours Lost reveal essentially zero correlations across the whole sample. Note though that from 1975 onwards there is a remarkable similarity in the movement (after re-scaling to match means and ranges) of capacity utilization and a measure of the output gap, defined as trend adjusted log output per capita - gap $t=(y-l){ }_{t}-0.005 t$ (see figure 4). The latter variable, which plays an important role in the subsequent analysis, can be interpreted for a constant returns Cobb Douglas technology as the deviation of output from capacity, or the log of output per capita as a deviation from capital per capita (proxied by trend). However, the graph of log labour share $\left(s_{t}=(w-p)_{t}-(y-l) t\right)$ in figure 4 shows a marked upward trend in the period 1970(1) to 1980(1) which is inconsistent with a Cobb Douglas technology, and not typical of the behaviour of labour share in a wider historical perspective. Indeed, the relatively constant mean that $s_{t}$ has after 1980 is more typical. Hence any equilibria that are estimated using sample data prior to 1980 could contain non-sustainable features, and thus differ from long run economic relationships even though they provide a good characterization of a particular sample of data.

From figure 3 the upward trend in total employment $(E m p)$ from 1973 is evident. There was an increased participation rate which was probably due to a mixture of demographic factors (such as the baby boom of the 1960s and a lower emigration rate), social factors (such as female emancipation), and economic factors (such as unemployment benefits). The increase in labour force is nearly matched by an increase in employment up to the late 1970s, but thereafter there is a marked slowdown in employment which underlies the increase in the unemployment rate. The big effects of the changes in definitions in 1992, and the events surrounding the exit of the lira from the EMS in September 1992, are clearly visible. Daveri and Tabellini (1997) argue that increases in labour taxation have also resulted in increased unemployment. As a final remark on labour force participation, note that the requirements for a person to be considered as a member of the labour force are less stringent in Italy and Europe generally than in the US. According to the results in Micali (1990), if the unemployment rate for Italy were calculated according to the US standards it would nearly halve.

In summary, there is ample informal evidence in the descriptive statistics presented above to suggest that the series to be analyzed in the following sections have different characteristics pre and post 1980. Similar informal evidence, contained in the following table giving sample means and standard deviations, shows there to be less volatility in all the price-related variables after 1980, with the same degree of volatility in the output-related variables in both periods. Although the mean of real wages increased after 1980 , the mean rate of inflation was substantially lower. The means of the output-related variables all increased after 1980. Also note that the rates of growth of $(w-p)_{t},(y-l)_{t}$, and the rate of acceleration of prices $\Delta^{2} p_{t}$ have very different means and standard deviations pre and post 1980 - higher and more volatile in the 1970s. There is however much less change in these statistics for $u_{t}$. 


\begin{tabular}{|c|c|c|c|c|c|c|}
\hline \multicolumn{7}{|c|}{ Table 1 Descriptive Statistics } \\
\hline \multicolumn{3}{|c|}{$70(3)-79(4)$} & \multicolumn{2}{|c|}{$80(1)-94(4)$} & \multicolumn{2}{|c|}{$70(3)-94(4)$} \\
\hline & Mean & $\mathrm{SD}$ & Mean & $\mathrm{SD}$ & Mean & SD \\
\hline$(w-p)_{t}$ & 3.235 & 0.108 & 3.526 & 0.083 & 3.413 & 0.170 \\
\hline$\Delta p_{t}$ & 0.031 & 0.015 & 0.021 & 0.013 & 0.025 & 0.015 \\
\hline$(y-l) t$ & 3.392 & 0.072 & 3.633 & 0.080 & 3.540 & 0.140 \\
\hline$u_{t}$ & 1.850 & 0.131 & 2.339 & 0.133 & 2.150 & 0.273 \\
\hline$\Delta(w-p)_{t}$ & 0.012 & 0.021 & 0.004 & 0.012 & 0.007 & 0.016 \\
\hline$\Delta^{2} p_{t}$ & 0.090 & 1.324 & -0.070 & 0.716 & -0.008 & 0.999 \\
\hline$\Delta(y-l) t$ & 0.007 & 0.010 & 0.004 & 0.006 & 0.005 & 0.008 \\
\hline$\Delta u_{t}$ & 0.009 & 0.063 & 0.007 & 0.045 & 0.008 & 0.052 \\
\hline
\end{tabular}

The presentation and discussion of the descriptive statistics above has concentrated on univariate and bivariate analysis, and is suggestive rather than definitive. Moreover, the inter-relationships amongst the variables of primary interest are multidimensional and dynamic. Hence attention is now turned to modelling a multivariate dynamic statistical system to characterise the evolution of wages, prices, output, and employment in Italy between 1970 and 1994.

\section{The Statistical Model}

Though the primary aim of this analysis is to develop a model of wage determination similar to those in Sargan (1964), it is done within a small system rather than a single equation. The descriptive statistics presented in Section 2 strongly indicate that most of the variables to be modelled are non-stationary, and in particular well represented as I (1) or I (2) variables. It is therefore essential to adopt a systems approach in order to accommodate the possibility of there being multiple cointegrating vectors. The set of variables that are potentially relevant for the explanation of wage determination in Italy is large (see Erickson and Ichino, 1994 and Bertola and Ichino, 1995), and so it is not possible to jointly model all of them using presently available system-modelling technology. Hence the value of the present modelling lies in the insights it yields into the properties of, and inter-relationships between, the chosen small set of variables. Although one of the findings is non-constancy in the equilibria of the system, it is important to note that once a system is non-constant, increasing the dimension of the system will not remove the non-constancy, irrespective of the properties of the additional variables. The non-constancy is simply reallocated to other equations, and leaves an equally complicated system to be modelled with different non-constancies. A similar argument applies to the approach of opening the system, by conditioning on variables (e.g., exchange rates and tax rates) that capture some of the underlying changes in the modelled variables, since forecasting will still require an explanation of the changes in the conditioning variables which in any case may not be weakly exogenous for the parameters of interest in wage determination.

The general system adopted for the subsequent analysis is a cointegrated VAR with deterministic 
variables (such as trend, and event specific dummies) included. The VAR is an important and commonlyused class of econometric model for linear dynamic processes. If the variables to be modelled cannot be well represented as a multivariate linear process then the VAR will not be congruent (see Bontemps and Mizon, 1996 and Hendry, 1995), and thus will exhibit signs of misspecification. Were this to be the case reformulation of the model (perhaps by variable transformation or by the inclusion of intervention dummy variables), will often enable the reformulated system to be well characterised by a VAR. Hence, provided that attention is paid to ensuring that it is congruent, the VAR can be expected to be a widely appropriate statistical model to use for modelling economic time series.

For $k$ lags on a vector of $n$ variables $\mathbf{x}_{t}$ with $n_{0}$ deterministic variables $\mathbf{q}_{t}$, the corresponding VAR is:

$$
\mathbf{x}_{t}=\sum_{j=1}^{k} \mathbf{A}_{j} \mathbf{x}_{t-j}+\mathbf{K q} \mathbf{q}_{t}+\boldsymbol{\epsilon}_{t} \text { with } \boldsymbol{\epsilon}_{t} \sim \operatorname{IN}_{n}(\mathbf{0}, \boldsymbol{\Sigma})
$$

When $\mathbf{A}_{j}$ is an $n \times n$ matrix of autoregressive coefficients, $\mathbf{K}$ is an $n \times m$ matrix of coefficients of the $n_{0}$ deterministic variables, and $\epsilon_{t}$ is a vector of $n$ unobserved errors which have a zero mean and constant covariance matrix $\Sigma$. When the variables being modelled $\mathbf{x}_{t}$ are $\mathbf{I}(1)$ but there are $r<N$ cointegrating vectors $\boldsymbol{\beta}^{\prime} \mathrm{x}_{t}$ which are I (0), the VAR (1) can be written as a vector equilibrium-correction mechanism (VE $q$ CM: see Johansen, 1988, 1992, and Hendry, 1995) which is a multivariate extension of the error/equilibrium correction mechanism introduced in Sargan (1964):

$$
\Delta \mathbf{x}_{t}=\sum_{j=1}^{k-1} \boldsymbol{\Gamma}_{j} \Delta \mathbf{x}_{t-j}+\boldsymbol{\alpha}\left(\boldsymbol{\beta}^{\prime} \mathbf{x}_{t-1}\right)+\mathbf{K} \mathbf{q}_{t}+\boldsymbol{\epsilon}_{t},
$$

where $\Delta$ is the first difference operator, $\boldsymbol{\Gamma}_{j}=-\sum_{i=j+1}^{k} \mathbf{A}_{i}$, and $\boldsymbol{\alpha}$ and $\boldsymbol{\beta}$ are $n \times r$ matrices of rank $r$ such that $\boldsymbol{\alpha} \boldsymbol{\beta}^{\prime}=-\left(\mathbf{I}_{N}-\sum_{i=1}^{k} \mathbf{A}_{i}\right)$. Identification restrictions are required to ensure uniqueness of $\boldsymbol{\alpha}$ and $\boldsymbol{\beta}$. The model in (2) is in I (0) space when correctly formulated, thus inference concerning its parameters $\boldsymbol{\Gamma}_{1}, \boldsymbol{\Gamma}_{2}, \ldots . \boldsymbol{\Gamma}_{s-1}, \boldsymbol{\alpha}, \mathbf{K}$ and $\Sigma$ can be conducted using conventional procedures. Since $r$ is not known a priori its value has to be determined empirically, and the procedure adopted in the next sections is the maximum likelihood one developed by Johansen (1988) as implemented in PcFiml 9.21 (see Doornik and Hendry, 1997).

The properties of this system are conveniently considered for a second-order system $(k=2)$. The possibility that $\mathbf{x}_{t}$ is $\mathbf{I}(2)$ is ruled out when the condition $\operatorname{rank}\left(\boldsymbol{\alpha}_{\perp}^{\prime} \mathbf{\Phi} \boldsymbol{\beta}_{\perp}\right)=n-r$ is satisfied, with $\boldsymbol{\Phi}=\left(\mathbf{I}_{n}+\boldsymbol{\alpha} \boldsymbol{\beta}^{\prime}-\boldsymbol{\Gamma}\right)$ being the mean-lag matrix, $\boldsymbol{\Gamma}_{1}=\boldsymbol{\Gamma}$, and $\boldsymbol{\alpha}_{\perp}$ and $\boldsymbol{\beta}_{\perp}$ are $n \times(n-r)$ satisfying $\boldsymbol{\alpha}_{\perp}^{\prime} \boldsymbol{\alpha}=\boldsymbol{\beta}_{\perp}^{\prime} \boldsymbol{\beta}=\mathbf{0}$, such that $\left(\boldsymbol{\alpha}: \boldsymbol{\alpha}_{\perp}\right)$ and $\left(\boldsymbol{\beta}: \boldsymbol{\beta}_{\perp}\right)$ are full rank $n$. Univariate analysis of correlograms and unit root statistics suggested that $w_{t}$ and $p_{t}$ might be I (2), so we have chosen to model jointly $(w-p)_{t}, u_{t},(y-l)_{t}$, and $\Delta p_{t}$ as I (1) variables with deterministic changes represented by a trend and dummy variables. ${ }^{3}$

Further, let $\mathbf{K q}_{t}=\delta$ be a vector of $n$ constants, which covers most issues of substance, then (2) becomes the $\mathrm{VE}_{q} \mathrm{CM}$ :

$$
\Delta \mathrm{x}_{t}=\boldsymbol{\delta}+\boldsymbol{\alpha} \boldsymbol{\beta}^{\prime} \mathrm{x}_{t-1}+\boldsymbol{\Gamma} \Delta \mathrm{x}_{t-1}+\boldsymbol{\epsilon}_{t}
$$

\footnotetext{
${ }^{3}$ Independent unpublished analysis of our data by Hanne Lyngesen has confirmed that there are no I (2) features in the specification that we adopt.
} 
As pointed out in Hendry and Mizon (1993), when both $\Delta \mathrm{x}_{t}$ and $\boldsymbol{\beta}^{\prime} \mathrm{x}_{t}$ are $\mathbf{I}(0)$, the variables grow at the vector rate $\mathrm{E}\left[\Delta \mathrm{x}_{t}\right]=\gamma$, and the $r$ dimensional equilibrium of the system is $\mathrm{E}\left[\boldsymbol{\beta} \mathrm{x}_{t}\right]$. The long-run solution of the system is $\boldsymbol{\alpha} \mathrm{E}\left[\boldsymbol{\beta}^{\prime} \mathrm{x}_{t}\right]=\left(\mathbf{I}_{N}-\boldsymbol{\Gamma}\right) \boldsymbol{\gamma}-\boldsymbol{\delta}$, so letting $\mathrm{E}\left[\boldsymbol{\beta}^{\prime} \mathrm{x}_{t}\right]=\boldsymbol{\mu}$ implies that

$$
\delta=\left(\mathbf{I}_{N}-\Gamma\right) \gamma-\boldsymbol{\alpha} \boldsymbol{\mu}
$$

and yields:

$$
\left(\Delta \mathrm{x}_{t}-\gamma\right)=\boldsymbol{\alpha}\left(\boldsymbol{\beta}^{\prime} \mathbf{x}_{t-1}-\boldsymbol{\mu}\right)+\boldsymbol{\Gamma}\left(\Delta \mathbf{x}_{t-1}-\gamma\right)+\boldsymbol{\epsilon}_{t}
$$

When $\mathbf{x}_{t}$ is $\mathbf{I}(1)$ and $r$ is correctly specified all terms in (5) have zero means, and since $\Delta\left(\beta \mathbf{x}_{t}\right)$ is the difference of a stationary variable, $\boldsymbol{\beta} \boldsymbol{\gamma}=\mathbf{0}$. These latter $r$ restrictions together with (4) identify $\boldsymbol{\gamma}$ and $\boldsymbol{\mu}$, although both $\delta$ and $\gamma$ are $n \times 1$ and $\boldsymbol{\mu}$ is $r \times 1$. When $\delta$ is restricted to lie in the cointegration space $(\boldsymbol{\delta}=-\boldsymbol{\alpha} \boldsymbol{\mu})$ the system has no growth since $\gamma=\mathbf{0}$.

In addition to requiring that $\mathbf{x}_{t}$ be at most $\mathbf{I}(1)$, the Johansen (1988) procedure for determining $r$ requires the parameters of the VAR to be constant. However it is well known that it can be difficult to distinguish between deterministic shifts and unit roots in linear I (1) systems (see for example Perron, 1989, Rappoport and Reichlin, 1989, Hendry and Neale, 1991, and Campos, Ericsson and Hendry, 1996). Hence statistics for testing parameter constancy have important roles to play in evaluating the relative merits of alternative models for time series variables which might be subject to regime shifts, and in assessing whether conditions required for the valid application of procedures such as that of Johansen (1988) are satisfied. In particular, since parameter non-constancy impinges on tests for the existence and dimension of cointegrating space it seems appropriate to test the hypothesis of parameter constancy prior to testing unit root hypotheses. In multivariate contexts this is the approach adopted for example by Clements and Mizon (1991) and Hendry and Mizon (1993), who used recursive estimation as a convenient and powerful approach to assessing parameter constancy. Recursive estimation is valuable in assessing the number and location of break points in a system. However, interest is sometimes focused on the possibility of a single break point, and there are a number of test statistics available for such hypotheses, for example the single equation test statistics described in Chow (1960) and the system test statistics as implemented in PcFiml (see Doornik and Hendry, 1997). These procedures are implemented in Section 6 to provide formal evidence of the presence of structural changes.

\section{First Period Analysis}

In the next two sections the results of estimating and evaluating a VAR like (1) for the split samples 19701979 and 1980-1994 are discussed. The general approach adopted to the modelling is that described in Mizon (1995). Clements and Mizon (1991) and Mizon (1995) provide a similar analysis for this sector of the UK, and Golinelli (1997) and Binotti (1994) related analyses for Italy. Golinelli (1997) modelled

\footnotetext{
${ }^{4}$ All the empirical results were obtained using GiveWin 1.25 and PcFiml 9.21 (Doornik and Hendry, 1997).

${ }^{5}$ Modigliani, Padoa Schioppa and Rossi (1986) and Baici (1992) adopt a more structural approach, relying on a Layard and Nickell (1985) type of model. Fabiani, Locarno, Oneto and Sestito (1996) focus on the effects of income policy on unemployment, with a particular emphasis on the most recent period. The review paper on wage determination in Italy by Sestito (1993) also provides some useful insights on unemployment, and further references.
} 
annual data for $(\Delta w, \Delta p, p r, v)$ (with $v=(\Delta w-\Delta p-p r)$ ), in our notation over the period 1951 to 1996, and found only one cointegrating vector. Binotti (1994) models a set of quarterly variables corresponding essentially to $\mathbf{x}_{t}^{* \prime}=\left(w_{t}, u_{t},(y-l)_{t}, p_{t}\right)$. It was possible to reproduce closely her results by modelling $x_{t}^{* \prime}$ as a VAR(5), estimated over her sample (1970(1)-1990(4)). Yet, this re-estimation suggested the existence of two cointegrating relationships and not one as reported in Binotti (1994). Moreover, $w_{t}$ and $p_{t}$ could be better represented as I (2) rather than I (1) processes, while the transformed variables $\mathbf{x}_{t}^{\prime}=\left((w-p)_{t}, u_{t},(y-l)_{t}, \Delta p_{t}\right)$ are all I (1).

From the discussion in Section 2 many other variables could be relevant for explaining the dynamic inter-relationships between wages, prices, unemployment, and output per capita, including interest and exchange rates and measures of fiscal and monetary policy. Initially, rather than attempt to model such a large system, attention is confined to modelling the 4 variables in $\mathbf{x}_{t}$ jointly with up to 4 lags, and deterministic components including an unrestricted constant, plus a trend restricted to lie in the cointegrating space. The following impulse dummies, each of which is associated with known events, were included to avoid the effects of outlying observations $D 732, D 733, D 762$. In 1973 there was a general increase in the price of raw materials and the first oil price shock in its third quarter. In the second quarters of both 1973 and 1976 there were substantial devaluations of the lira - more than $10 \%$ with respect to the US dollar and the Deutschemark.

In determining dynamics of the VAR sequential likelihood ratio tests indicate that the third lag of the variables is not required, while the second one is. Hence an unrestricted VAR(2) for $\mathrm{x}_{t}$ was estimated by OLS for the sample 1970(4) to 1979(4), and Table 2 presents the single equation and vector diagnostic test statistics, with associated p-values given in square brackets. The included statistics are: single equation residual standard deviations $\hat{\sigma}, p^{t h}$ order serial correlation $A R(p)$, heteroscedasticity $H$, $q^{\text {th }}$ order autoregressive heteroscedasticity $A R C H(q)$, normality $N$ test statistics; and their system versions when enough degrees of freedom are available (see Doornik and Hendry (1997) for more details). On the basis of the outcome of these tests, none of them reject the null hypothesis at the $5 \%$, it is reasonable to conclude that this is a congruent unrestricted VAR.

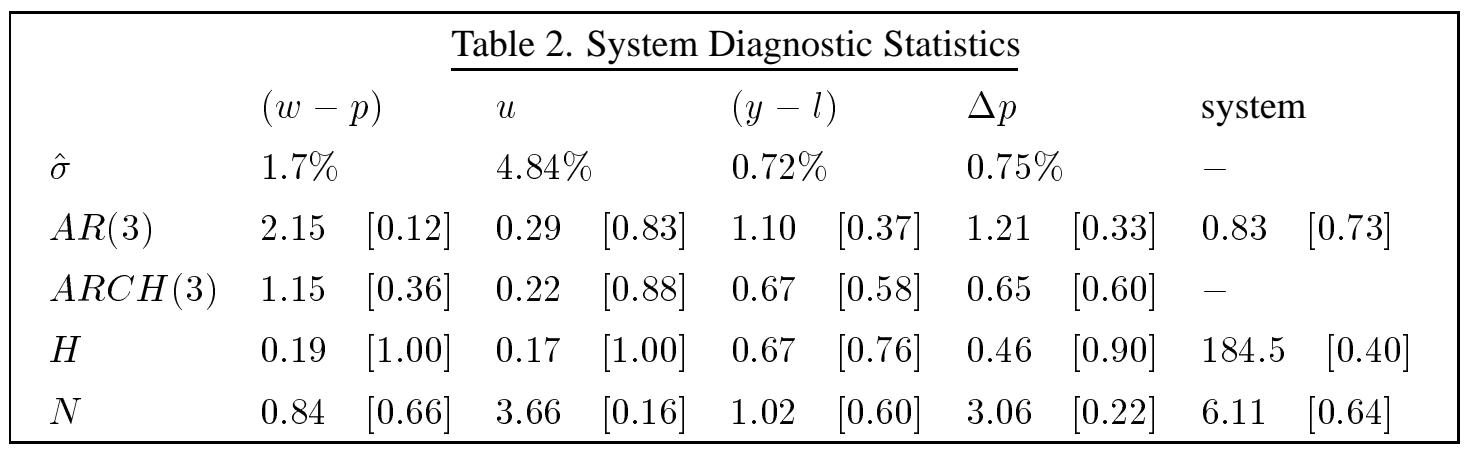

The next step was the determination of $r$, the number of equilibrium relationships among the variables. Table 3 reports the results for Johansen's Max $\left(=-T \ln \left(1-\mu_{r}\right)\right)$ and Trace $(=$ $\left.-T \sum_{i=1}^{r} \ln \left(1-\mu_{i}\right)\right)$ test statistics, together with the values of the eigenvalues, $\mu_{i}$, and the value of the maximized likelihood function apart from a constant (which is defined as $l=-T / 2 \sum_{i=1}^{r} \ln \left(1-\mu_{i}\right)$ ) (see Johansen, 1988 or Johansen, 1995 for details). The Max and Trace test statistics are not adjusted 
for degrees of freedom, and the critical values used are given in Osterwald-Lenum (1992); ${ }^{*}$ and ** indicate rejection at the $5 \%$ and $1 \%$ level of the hypothesis that the rank is $\leq(r-1)$. We note that Doornik, Nielsen and Hendry (1998) recommend use of the Trace statistic without degrees of freedom adjustment. The first two eigenvalues $\mu_{i}$ are substantial, suggesting that $\hat{r}=2$ might be appropriate. Actually, they are significantly different from zero on the basis of the maximum eigenvalue and trace test statistics, so that we continue the analysis under the hypothesis that $\hat{r}=2$.

\begin{tabular}{|ccccc|}
\hline \multicolumn{5}{c}{ Table 3: Cointegration Statistics } \\
\cline { 2 - 5 } & 1 & 2 & 3 & 4 \\
$l$ & 648 & 662 & 669 & 671 \\
$\mu$ & 0.66 & 0.52 & 0.33 & 0.09 \\
Max & $39.36^{* *}$ & $27.35^{*}$ & 14.94 & 3.41 \\
Trace & $85.07^{* *}$ & $45.71^{*}$ & 18.35 & 3.41 \\
\hline
\end{tabular}

Table 4 shows the first sample equilibria resulting after imposing non-rejected over-identifying restrictions that were tested using a LR statistic, (when $e q m a_{1 i}$ indicates the $\mathrm{i}^{\text {th }}$ mean-adjusted equilibrium correction term given by $\left(\boldsymbol{\beta}^{\prime} \mathbf{x}_{t-1}-\boldsymbol{\mu}\right)$ in equation (5) with $\hat{\boldsymbol{\mu}}_{11}=-1.91$ and $\hat{\boldsymbol{\mu}}_{12}=-2.66$ ), and their related adjustment coefficients $\hat{\boldsymbol{\alpha}}_{i}$ (standard errors are in parentheses).

\begin{tabular}{|c|c|c|c|}
\hline \multicolumn{4}{|c|}{ Table 4: First Period Equilibria $(\hat{r}=2)$ and Adjustment Coefficients } \\
\hline$e q m a_{11, t}=s_{t}+0.12 u_{t}-0.58(y-l)_{t}+1.91$ & $\hat{\boldsymbol{\alpha}}_{i}$ & $i=1$ & $i=2$ \\
\hline & $(w-p)_{t}$ & $-\begin{array}{r}0.39 \\
(0.15)\end{array}$ & $\begin{array}{c}0.87 \\
(0.29)\end{array}$ \\
\hline$e q m a_{12, t}=\Delta p_{t}+0.09 u_{t}-0.88((y-l) t t-0.005 t)+2.69$ & $u_{t}$ & 0 & 0 \\
\hline$\chi^{2}(2)=1.18 \quad[0.56]$ (equilibria) & $(y-l) t$ & $\begin{array}{r}0.24 \\
(0.05)\end{array}$ & 0 \\
\hline$\chi^{2}(5)=2.75 \quad[0.74]$ (equilibria and feedback) & $\Delta p_{t}$ & $\begin{array}{r}0.20 \\
(0.06)\end{array}$ & $-\begin{array}{r}0.68 \\
(0.12)\end{array}$ \\
\hline
\end{tabular}

The resulting first relationship indicates that labour share decreases with unemployment and increases with output per capita. The negative effect of unemployment is similar to that found in the wage equation reported in Sargan (1964), and can be interpreted as weak demand for labour ceteris paribus leading to a fall in labour share. In addition, labour share increasing with output per capita can be interpreted as a signal of the strong power of employed labour (higher output per capita is accompanied by higher real wages), combined with the consequences of the wage indexation system ("Scala Mobile") that was introduced in 1975.6 Also recall that labour share, unusually, increased throughout this period. This equilibrium term exerts a significant effect on the rates of growth of all the variables, except unemployment, and the signs of the reactions are as expected.

The second relationship admits an augmented Phillips curve interpretation. Inflation decreases with increases in unemployment, but increases with excess output per capita (positive deviations of output per

\footnotetext{
${ }^{6}$ Dummy variables associated with this event were not statistically significant.
} 
capita from its sample trend), which can be also considered as a proxy for excess demand or the output gap as discussed earlier. Deviations from this equilibrium significantly affect real wages and inflation.

Further inspection of the estimated adjustment coefficients $\hat{\alpha_{z}}$ shows that unemployment is uninfluenced by any of the disequilibria, and so it is weakly exogenous for the parameters of these first sample equilibria. As a consequence, one of the two stochastic trends driving the system is represented by the cumulated residuals of the unemployment equation. This provides preliminary evidence in favour of an hysteresis explanation for unemployment in the 1970s, namely, shocks to the unemployment rate tend to have permanent effects by increasing the natural rate of unemployment, see e.g. Blanchard and Summers (1988).

The $\mathrm{VE}_{q} \mathrm{CM}$, where the first differences of the variables are regressed on their first lags, a constant and the two equilibrium relationships in Table 4, is also congruent. It was therefore used as a basis to derive a reduced model in terms of the rates of growth of the variables. The results of FIML estimation are reported in Table 5, together with diagnostic tests. The reduced model imposes 22 over-identifying restrictions, that are accepted by a LR test $\left(\chi^{2}(22)=24.86[0.30]\right)$, and none of the diagnostic statistics indicates a problem with this specification.

\begin{tabular}{|c|c|c|c|c|c|c|c|c|c|}
\hline \multicolumn{10}{|c|}{ Table 5: First Period Reduced Model } \\
\hline$\Delta(w-p)_{t}$ & \multicolumn{9}{|c|}{$=-\underset{(0.11)}{0.25} e q m a_{11, t-1}+\underset{(0.19)}{0.52} e q m a_{12, t-1}+\underset{(0.003)}{0.013}+\underset{(0.02)}{0.05} D 733$} \\
\hline$\Delta u_{t}$ & \multicolumn{9}{|c|}{$=\underset{(0.05)}{0.15} D 732-\underset{(0.05)}{0.24} D 733$} \\
\hline$\Delta(y-l)_{t}$ & \multicolumn{9}{|c|}{$=\underset{(0.04)}{0.21} e q m a_{11, t-1}+\underset{(0.11)}{0.27} \Delta(y-l)_{t-1}-\underset{(0.02)}{0.04} \Delta u_{t-1}+\underset{(0.001)}{0.003}$} \\
\hline \multirow[t]{2}{*}{$\Delta^{2} p_{t}$} & \multicolumn{9}{|c|}{$=\underset{(0.05)}{0.18} e q m a_{11, t-1}-\underset{(0.08)}{0.63} e q m a_{12, t-1}-\underset{(0.05)}{0.18} \Delta(w-p)_{t-1}-\underset{(0.08)}{0.57} \Delta^{2} p_{t-1}$} \\
\hline & $\Delta(w-p)$ & $\Delta u$ & & $\Delta(y-$ & $-l)$ & $\Delta^{2} p$ & & systen & \\
\hline$\hat{\sigma}$ & $1.74 \%$ & $4.75 \%$ & & $0.72 \%$ & & $0.72 \%$ & & - & \\
\hline$A R(3)$ & $1.74 \quad[0.19]$ & 1.62 & {$[0.21]$} & 1.48 & {$[0.24]$} & 2.39 & {$[0.09]$} & 0.99 & {$[0.51]$} \\
\hline$H$ & $0.93[0.56]$ & 0.36 & {$[0.97]$} & 0.87 & {$[0.60]$} & 1.41 & {$[0.29]$} & 0.90 & {$[0.72]$} \\
\hline$A R C H(3)$ & $0.32 \quad[0.81]$ & 0.39 & {$[0.76]$} & 0.05 & {$[0.99]$} & 0.71 & {$[0.56]$} & - & \\
\hline$N$ & $1.24 \quad[0.54]$ & 1.61 & {$[0.45]$} & 3.26 & {$[0.20]$} & 0.87 & {$[0.65]$} & 6.16 & {$[0.63]$} \\
\hline
\end{tabular}


A first characteristic to be noted is that no contemporaneous variables are significant in the equations. This might be a consequence of the level of temporal aggregation of the data - see e.g. Marcellino (1999). The growth of real wages depends mainly on deviations from both equilibria, with the appropriate signs. It is remarkable that unemployment has no direct short run effect on real wages, even though it is involved in the real wage equilibrium eqma $a_{11, t}$. Unemployment appears to be a random walk without drift in this period, which accords with it being weakly exogenous for the long run parameters of the system, and provides further evidence for the hysteresis theory. The growth of output per capita is affected primarily by its own lag, suggesting a certain degree of persistence, by lagged changes in unemployment, and by the first equilibrium with an appropriate adjustment coefficient. Finally, the change in inflation is related to both equilibria, to its own lag, to past growth in real wages, and has no autonomous drift.

\section{Second Period Analysis}

Attention is now turned to modelling $\mathrm{x}_{t}$ in the period 1980(1)-1994(4), and comparing the results with those for the 1970s in the previous section. The starting point is again the construction of a congruent VAR for the variables, which provides the basis for the statistical analysis. The following deterministic variables were included: a constant, a trend (restricted to lie in the cointegrating space), three step dummies Divorce (1981(3) and 1981(4)) when there was a devaluation and the 'divorce' between the Bank of Italy and the Treasury, D92Shift (covering 1992(4) to 1993(4)) a period of strong devaluation following the exit of the lira from the EMS, De flate for the tight monetary policy leading to a recession in the period 1980(1) to 1982(2), plus DUnemp (1992(4) minus 1993(2)) for the change in definition of unemployment. The role of DUnemp (which was entered unrestrictedly in the cointegrated VAR) in correcting for data mis-measurement is illustrated by the graphs of $u_{t}$ and $u a_{t}$ in figure 4 , when $u a_{t}$ is unemployment adjusted for the change in definition obtained as the residual from regressing $w$ on the partial sum $\sum_{i=1}^{t}$ DUnemp $p_{i}$ over the sample 1980(1) - 1994(4). In fact, $u a_{t}=u_{t}+0.11833 \sum_{i=1}^{t}$ DUnemp . The fact that the resulting estimates are essentially invariant to re-estimation with data to 1992(3) only, lends support to the use of this dummy variable. Simplifying the dynamics whilst requiring the VAR to be congruent, led to the choice of lag length two, as in the first period.

Table 6 indicates that the resulting VAR(2) passes all diagnostic controls, with borderline values only for the normality test in the real wage equation and the serial correlation test for the output per capita equation.

\begin{tabular}{|c|c|c|c|c|c|c|c|c|c|c|}
\hline \multicolumn{11}{|c|}{ Table 6. System Diagnostic Statistics } \\
\hline & \multicolumn{2}{|c|}{$(w-p)$} & \multicolumn{2}{|l|}{$u$} & \multicolumn{2}{|c|}{$(y-l)$} & \multicolumn{2}{|l|}{$\Delta p$} & \multicolumn{2}{|c|}{ system } \\
\hline$\hat{\sigma}$ & $0.90 \%$ & & 3.21 & & 0.54 & & 0.46 & & - & \\
\hline$A R(4)$ & 0.90 & {$[0.47]$} & 0.38 & {$[0.82]$} & 2.47 & {$[0.06]$} & 1.91 & {$[0.13]$} & 0.81 & {$[0.83]$} \\
\hline$H$ & 0.19 & [1.00] & 0.66 & {$[0.82]$} & 1.18 & {$[0.34]$} & 1.28 & {$[0.28]$} & 0.72 & [0.99] \\
\hline$A R C H(4)$ & 1.85 & {$[0.14]$} & 0.36 & {$[0.84]$} & 0.31 & {$[0.87]$} & 0.57 & {$[0.69]$} & - & \\
\hline$N$ & 5.86 & {$[0.05]$} & 0.39 & {$[0.82]$} & 2.48 & {$[0.29]$} & 1.30 & {$[0.52]$} & 10.5 & {$[0.23]$} \\
\hline
\end{tabular}


The Max and Trace statistics in Table 7 indicate that $r \geq 1$ is appropriate. In view of the small sample, and the fact that the critical values used do not allow for the dummy variables, we chose $\hat{r}=$ 2 . This is further supported by the eigenvalues of the companion matrix having a complex pair with modulus 0.93 , and the next largest eigenvalue being 0.73 . The congruence of the restricted $\mathrm{VE} q \mathrm{CM}$ which includes the two equilibrium correction terms in Table 8 , and their strong statistical significance, provide further support for this hypothesis.

\begin{tabular}{|ccccc|}
\hline \multicolumn{5}{c}{ Table 7: Cointegration Statistics } \\
\cline { 2 - 5 }$r$ & 1 & 2 & 3 & 4 \\
$l$ & 1151 & 1160 & 1167 & 1173 \\
$\mu$ & 0.68 & 0.25 & 0.21 & 0.19 \\
Max & $68.38^{* *}$ & 16.88 & 13.74 & $12.71^{*}$ \\
Trace & $111.7^{* *}$ & $43.33^{*}$ & $26.45^{*}$ & $12.71^{*}$ \\
\hline
\end{tabular}

Table 8 shows the second period equilibria $\left(e q m a_{2 i}\right)$ resulting from imposing non-rejected overidentifying restrictions, and their related adjustment coefficients (standard errors are in parentheses).

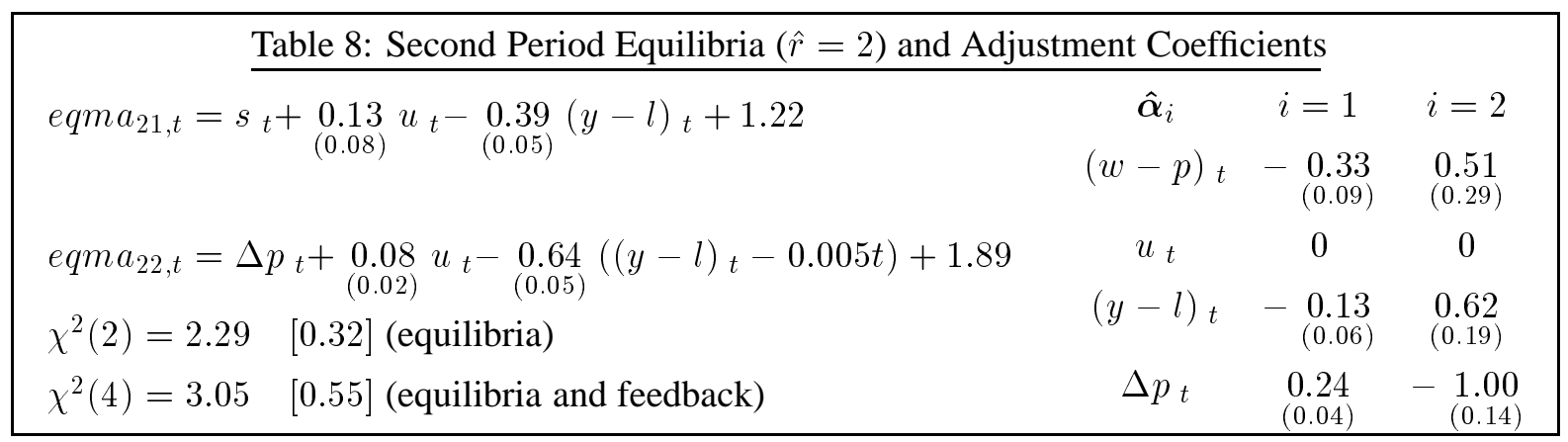

The number of equilibria is equal in the first and second periods, these equilibria satisfy the same two over-identifying restrictions, have similar interpretations, and the coefficient of trend in the output gap variable, gap $_{t}=(y-l)_{t}-0.005 t$, is the same for both periods. However, the coefficients of output per capita change markedly across the two periods. In the first equilibrium, labour share still decreases with unemployment and increases with output per capita, though the absolute value of the coefficient of the latter is $27 \%$ smaller than its value in the 1970 s. This change probably reflects a decline in labour power - recall the decrease in hours lost in labour disputes (figure 3) - and the modifications leading to the abolition of the wage indexation system in the early 1980s.

In the second equilibrium, the Phillips curve, the coefficient of unemployment is virtually the same as in the 1970s, but that of the output gap decreases in absolute value by $12 \%$. This can be interpreted 
as demand shocks having a lower effect on inflation, which is probably due to the more active monetary policy specifically aimed at reducing inflation. This latter interpretation though suggests that eqma2,t might be better normalized on the output gap.

$u_{t}$ remains weakly exogenous for the long run parameters so that unemployment is still one of the two stochastic trends driving the system, which remains consistent with an hysteresis interpretation. On the other hand the adjustment coefficients of $(y-l)_{t}$ to both equilibria are markedly different, which again probably reflects the changed relationship between output per capita and the wage and price variables resulting from the changed policy stance on inflation.

The unrestricted $\operatorname{VE} q \mathrm{CM}$ using the mean-adjusted equilibria from Table 8, eqma $a_{21, t}$ and $e q m a_{22, t}$, when estimated by OLS was congruent. Hence a simplified model was developed, the FIML estimates for which are reported in Table 9. This reduced model parsimoniously encompasses the unrestricted $\operatorname{VE} q \mathrm{CM}\left(\chi^{2}(25)=18.65 \quad[0.81]\right)$. As in the 1970s, no contemporaneous variable proved relevant, which is compatible with the type of variables under analysis. None of the single equation diagnostic statistics indicates a serious problem, though there is some serial correlation in the $(y-l)_{t}$ residuals and heteroscedasticity in those of the $\Delta^{2} p_{t}$ equation. All the system diagnostics are satisfactory.

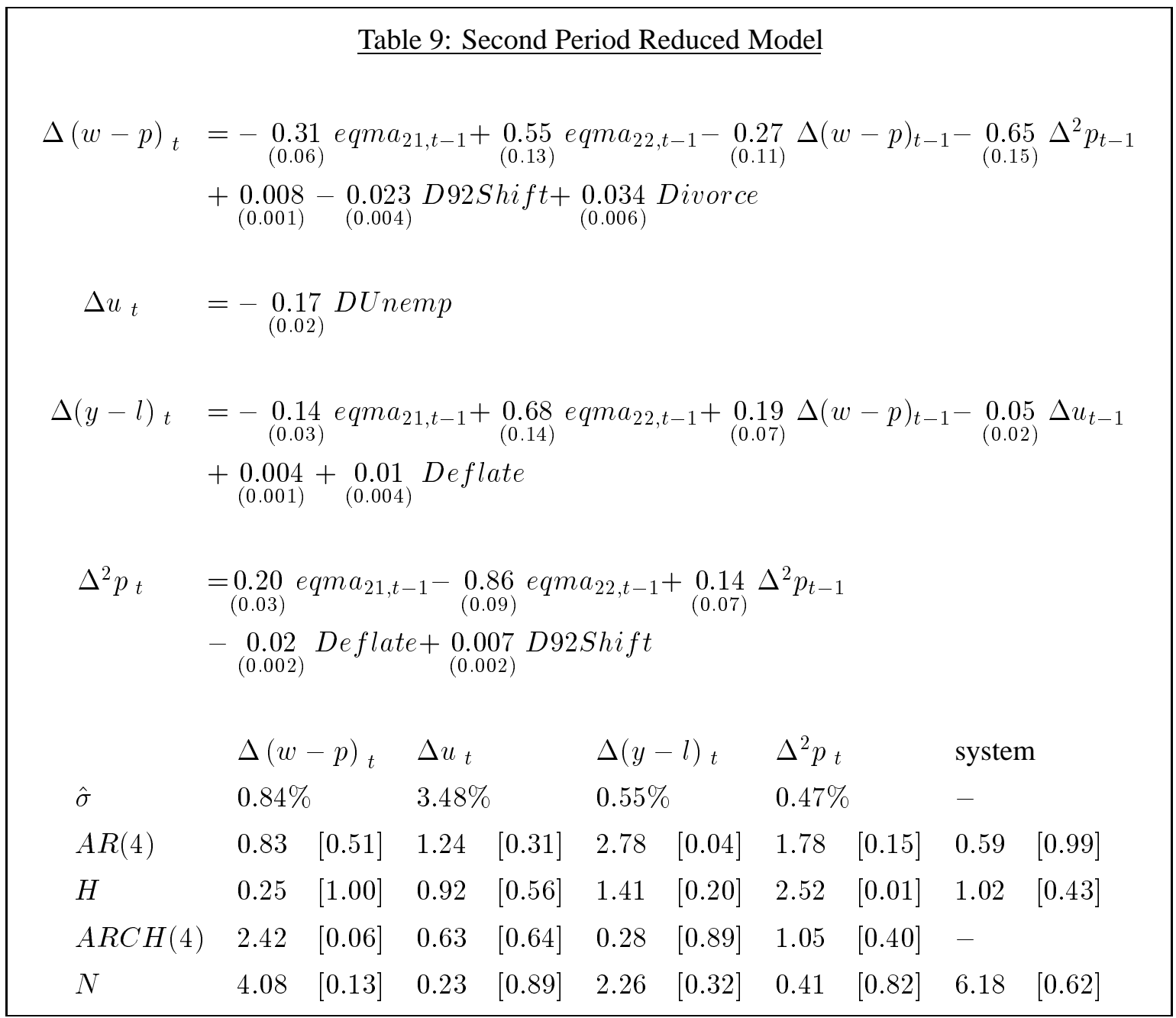


From Table $9, \Delta(w-p)_{t}$ reacts negatively to both past changes in inflation and to its own past growth. In addition, it adjusts appropriately to both equilibrium correction terms, and has a positive drift of about 3\% per annum, which is lower than in the 1970s and further decreases in the final part of the sample (as measured by the coefficient of D92Shift), as a consequence of the changes in the wage setting process introduced in July 1992. The rate of growth of unemployment is a random walk in this small system, but is affected by the change in definition via the DUnemp dummy variable. Hence, as in this first period, unemployment is modelled as an integrated process unaffected by the other variables in the system, which is coherent with the hysteresis theory and it being weakly exogenous. Growth in output per capita reacts appropriately to $e q m a_{21, t-1}$ and $e q m a_{22, t-1}$, negatively to real wage disequilibrium and positively to inflation disequilibrium respectively. This is a change from the results for the 1970s in which output per capita growth only depended on $e q m a_{1, t-1}$. It also reacts appropriately to lagged growth in real wages and unemployment, and has an autonomous drift of about $1.5 \%$ which is lower than that in the 1970s. The reaction of price acceleration to the two equilibria is normal, and there is no drift, which is reassuring to guarantee a stable low level of inflation, as required by the Maastricht Treaty. In addition, the negative response to De flate indicates the success of the tight monetary policy in the early 1980s. The positive coefficient on D92Shift appears to be offsetting for the declining values of $e q m a_{21, t}$ at the end of the sample.

In summary, unemployment is well modelled as an integrated process unaffected by the other variables in the system for the whole period 1970-1994, which provides support for an hysteresis interpretation. However, after 1980 there were changes both in the equilibria and in the dynamic evolution of the other variables under analysis, especially real wages and inflation. Inflation responds less to demand shocks (lower coefficient on $(y-l)_{t}$ in eqma $a_{2, t}$ ), and much more to eqma $a_{22, t}$ in the second period. Also, the institutional and policy changes that took place in the 1980s appear to have led to wage moderation, with real wages evolving in line with output per capita but not inflation, but still not reacting to increased unemployment in the latter part of the sample. The major changes in both the equilibria and the nature of the reduced model between the two periods lies in the role of output per capita.

\section{Evidence of Structural Change}

From the graphs in Section 2 it was evident that there was a marked change in the behaviour of several variables in the late 1970s or early 1980s, associated with major changes in the institutional setting. The results in Sections 4 and 5 provide some support for this hypothesis, by highlighting substantial differences both in the short run dynamics and in the equilibrium relationships amongst the variables, especially $(y-l)_{t}$, in the two sub-periods. In this section we analyze this issue in more detail, noting that recursive estimation techniques, a powerful tool for stability analysis, are not very useful in our case since the number of observations required to initialize the procedure only allows us to evaluate reliably whether stability holds from the mid 1980s onwards.

Firstly, we note that even if the VAR and the reduced model are congruent and provide good statistical representations for the variables in the 1970s (see Section 4), they perform badly in forecasting 
all variables in the 1980s and early 1990s. Figures 5 and 6 give the 1-step ahead forecasts for the period 1980(1) to 1994(4) using the first period unrestricted VAR, and dynamic forecasts for the same period using the reduced model respectively. The major forecast failures are over-prediction of $(w-p)_{t}$ and under-prediction of $\Delta p_{t}$, which are primarily due to the changed coefficient of $(y-l)_{t}$ in the two equilibria across the two periods leading in turn to the changes in the equilibrium means noted above. Also notice that the unemployment equation fails to explain the change in definition of 1992(4) which was unknown in 1979(4). The difference in the estimated cointegrating coefficients between the two regimes yields corresponding shifts in the means of the equilibria - the means of the two equilibria for the first regime are $\hat{\mu}_{11}=-1.91$ and $\hat{\mu}_{12}=-2.69$, whereas those for the second regime are $\hat{\mu}_{21}=-1.22$ and $\hat{\mu}_{22}=-1.89$. One of the key findings in Clements and Hendry (1999) is that shifts in the equilibrium means are a major cause of predictive failure, hence it is not a surprise that the first regime model suffers forecast failure in the second period. Formal statistical tests for forecast failure are presented in Table 10. Hendry, 1995 page 435 gives the definition of the Wald test statistic $F 1$ used below. $F 2$ differs from $F 1$ by taking into account parameter uncertainty in computing the variance-covariance matrix of the forecast errors, see Doornik and Hendry (1994) for further details. As to be expected both $F 1$ and $F 2$ strongly indicate forecast failure.

\begin{tabular}{|c|c|c|}
\hline \multicolumn{3}{|c|}{$\underline{\text { Table 10. Forecast Statistics }}$} \\
\hline & $F 1$ & $F 2$ \\
\hline $\operatorname{VAR}(240,24)$ & $20.05^{* *}[0.00]$ & $2.54^{* *}[0.00]$ \\
\hline Model $(240,33)$ & $5.11^{* *}[0.00]$ & $3.62^{* *}[0.00]$ \\
\hline $\operatorname{DDVAR}(240,33)$ & $0.52 \quad[1.00]$ & $0.50 \quad[1.00]$ \\
\hline
\end{tabular}

Clements and Hendry (1999) show that forecasts based on modelling $\Delta^{2} \mathrm{x}_{t}$ in a VAR are robust to in-sample shifts in equilibrium means. The statistics given for the DDVAR in Table 10 in showing the absence of forecast failure illustrate this result, and provide further confirmation of the hypothesis that there was an important change in the equilibria.

Secondly, the evidence for a single regime, rather than two separate regimes, providing an adequate characterization of the data was evaluated directly. An unrestricted VAR(2) for $\mathrm{x}_{t}$ with a constant, restricted trend, and the seven dummy variables that were used in the split sample analysis included, was estimated by OLS for the sample 1970(4) to 1994(4). The result was a highly non-congruent model, as evidenced by the system serial correlation test $F(80,227)=1.52 \quad[0.01]$ and vector normality test $\chi^{2}(8)=15.98 \quad[0.04]$. Although the major reason for the non-congruence of the full sample model appeared to be outliers, increasing the lag length to 5 did not improve the results. Further, though it was possible to get a model in which none of the diagnostic test statistics was significant by introducing additional dummy variables, the resulting cointegration analysis was inconclusive on the number of cointegrating vectors ( $r=1$ or 2 ), and the equilibria were difficult to interpret economically. Furthermore, although the estimated unrestricted $\operatorname{VAR}(2)$ for $\mathrm{x}_{t}$ with a constant, restricted trend, the seven dummy variables, plus a step dummy for the second period restricted to lie in the cointegrating space, was congruent and indicated that $\hat{r}=2$, the resulting equilibrium coefficient estimates were very different from 

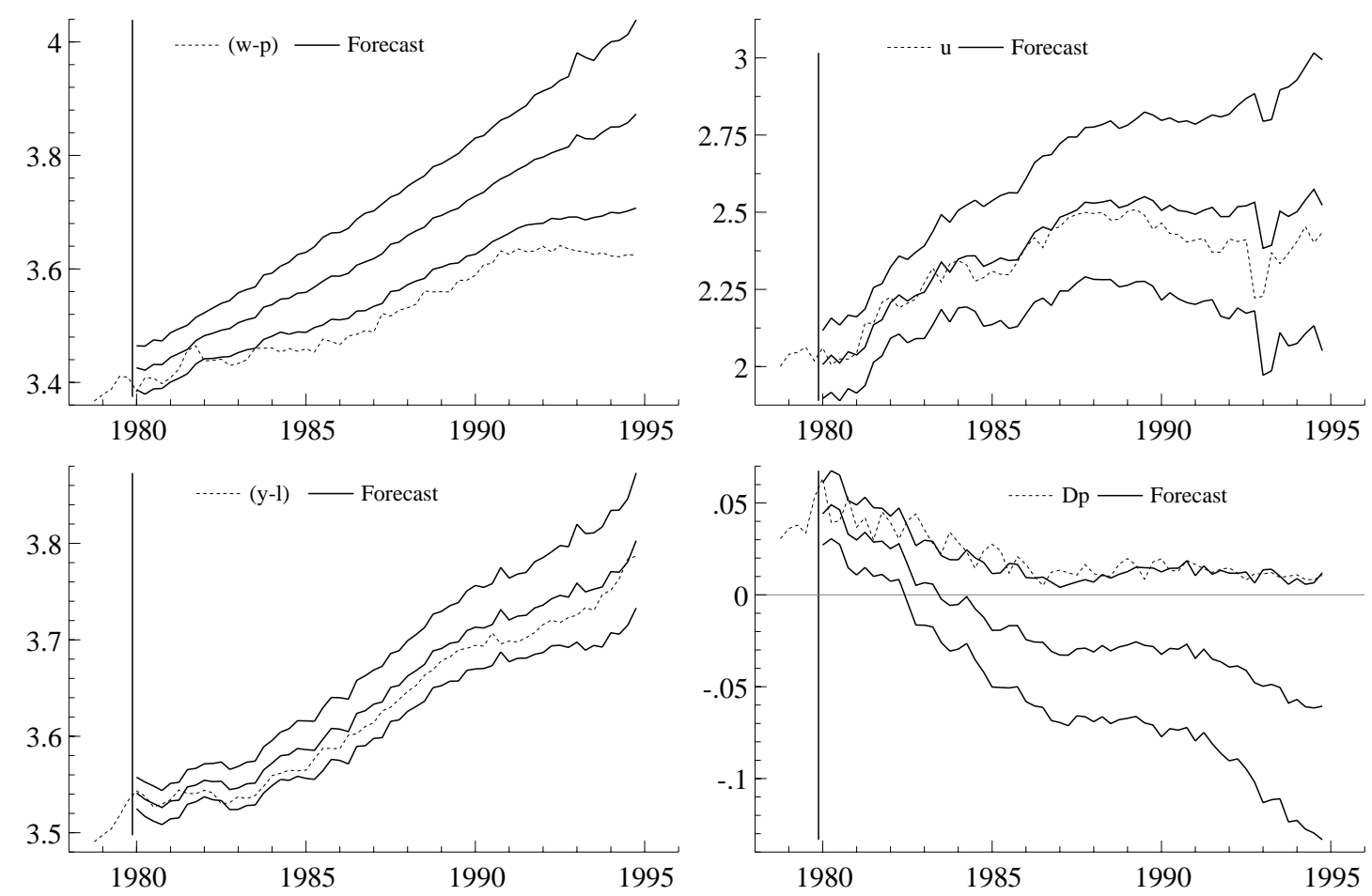

Figure 5 First regime VAR 1-step ahead forecasts.
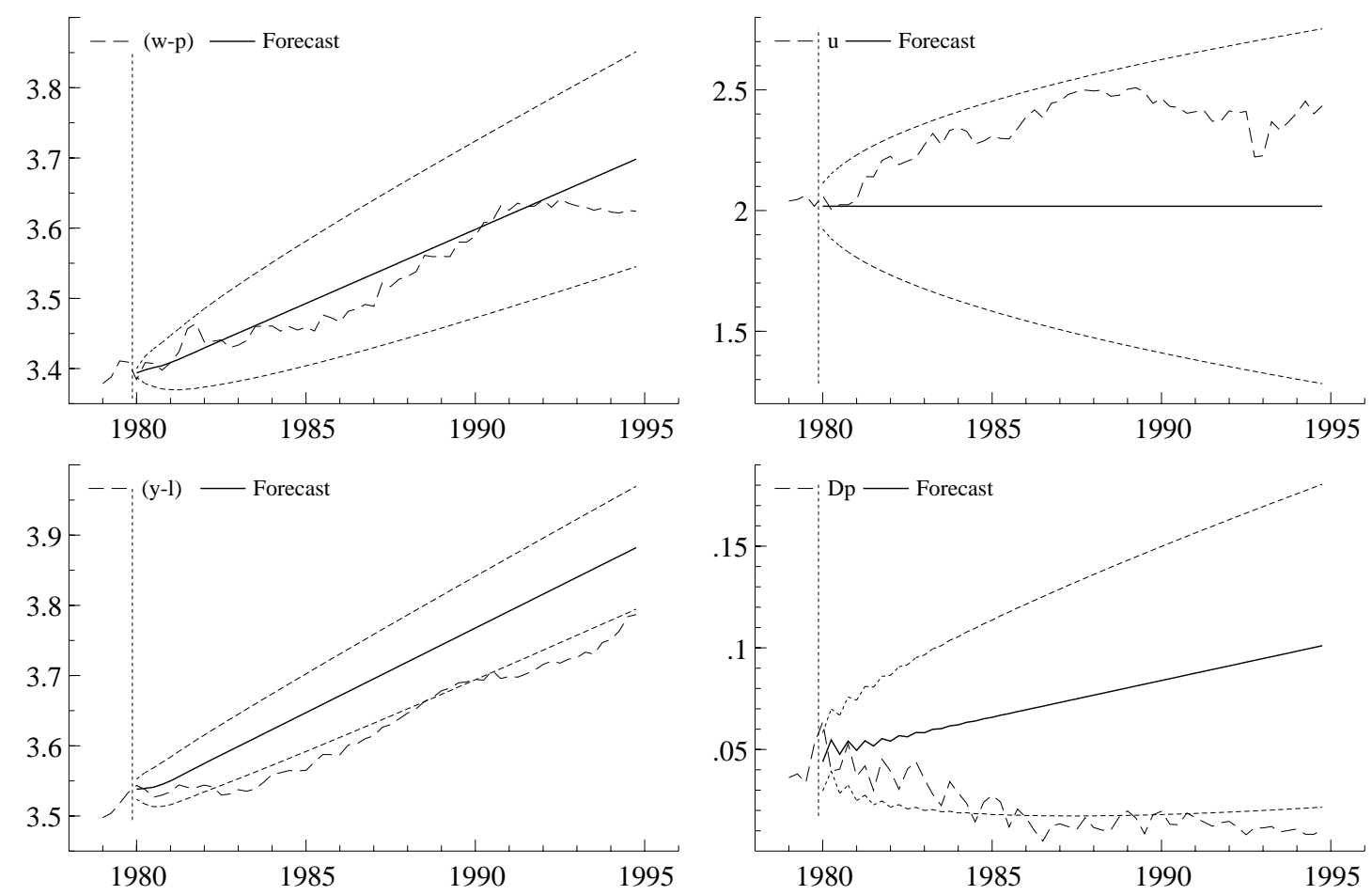

Figure 6 First regime model dynamic forecasts.

those in either Table 4 or Table 8 and difficult to interpret.

As a third possibility, we evaluated whether the structural changes in the Italian economy could be 
captured by some of the variables that we described in Section 2. In particular, we considered the role of the real interest rate, as a proxy for monetary policy, the effective exchange rate and the net trade balance weighted by GDP, to take into account the fact that Italy is an open economy, and the hours lost in labour disputes, as a proxy for the importance of unions and more generally for the climate in the labour market. Up to four lags of each variable were included as exogenous regressors in a VAR for the full sample period, and non significant variables were sequentially eliminated. The resulting specification passes all diagnostic tests, and therefore it appears that the exogenous variables manage to proxy reasonably well the changing characteristics of the economy. Yet, when the model is used for forecasting the behaviour of the variables from the early 1980s onwards or from the late 1980s onwards, there are major forecast failures. This illustrates the argument presented in Section 3 that conditioning on variables (e.g., exchange rates and tax rates) that capture some of the underlying changes in the modelled variables cannot remove forecast failure, since forecasting will still require an explanation of the changes in the conditioning variables.

Hence despite the non rejection of the same restrictions on the equilibria of the two periods, and the fact that resulting restricted equilibria were broadly similar, there is strong evidence suggesting that the equilibria in the two periods are different. We conclude that the split-sample analysis of Sections 4 and 5 remains more reliable than the alternatives considered.

\section{Conclusions}

This paper has illustrated the potential value of equilibrium correction mechanisms for small system modelling of the evolution of wages, prices, output per capita, unemployment, and inflation similar to the single equation modelling done by Denis Sargan in his famous paper Sargan (1964), but for an economy subject to substantial structural change. Modelling macroeconomic time series for economies that have experienced considerable change is both a challenge and potentially highly informative about underlying structural relationships. Economies that present these opportunities are of many types: two leading examples are the economies of central and eastern Europe which have moved from being centrally planned to using decentralized markets; and the economies of western Europe that have relied less on Keynesian polices and more on monetarist ones, as well as undertaking major programmes of de-regulation and privatization. Attempting to model the evolution of wages, prices, inflation, output per capita, and unemployment in such economies is prone to many difficulties. The many changes that took place in the foreign exchange and labour markets, in monetary and fiscal policy, and in financial deregulation, are probably linked to these difficulties. Noting the turbulence in this sector of the Italian economy between 1970 and 1994, it has been important to adopt methods of accommodating change within the framework of the vector equilibrium correction model. These have included choice of lag length, the use of dummy variables, modelling conditionally on related macroeconomic variables, and modelling separate regimes. The last provides an illustration of the fact that equilibrium correction mechanisms do not error correct to changes in equilibrium means and growth rates, and is the most satisfactory option considered. 


\section{Data Appendix}

The data are quarterly seasonally adjusted for the period 1970(1) to 1994(4), seasonally unadjusted data for these all variables being unavailable. By units of labour is meant the number of employed people without allowance for number of hours of work. This is a potential source of difficulty since some flexibility in the employment of labour is achieved via varying the hours of work. Equally, if the composition of the labour force - self-employed and non self-employed - has changed over time this may have an important influence on the data being analysed. Total earnings are the nominal earnings plus social insurance contributions for non self-employed workers (including professional, manual, and services).

\begin{tabular}{|c|c|c|c|}
\hline \multicolumn{4}{|c|}{ Table A1. Definitions of variables } \\
\hline & & & Source \\
\hline$W$ & wages & $\frac{\text { total earnings non self employed }}{\text { units of labour non self employed }}$ & ISTAT \\
\hline$P$ & prices & CPI $(1990=100)$ & ISTAT \\
\hline$U$ & unemployment & $\begin{array}{l}\% \text { unemployment rate } \\
\text { for total employment }\end{array}$ & ISTAT \\
\hline$Y$ & GDP & GDP (constant 1985 prices) & ISTAT \\
\hline$Y / L$ & output per capita & $\frac{\text { GDP }}{\text { total units of all labour }}$ & ISTAT \\
\hline$M 2$ & M2 money & & ISTAT \\
\hline Eff Exch & $\begin{array}{c}\text { effective exchange } \\
\text { rate }\end{array}$ & $\begin{array}{l}\text { trade weighted exchange } \\
\text { rate }(1990=100)\end{array}$ & $\begin{array}{l}\text { OECD } \\
1656009 \mathrm{H}\end{array}$ \\
\hline$R$ & interest rate & $\begin{array}{l}\text { long term Treasury } \\
\text { bond rate }(\% \mathrm{pa})\end{array}$ & $\begin{array}{l}\text { OECD } \\
165578 \mathrm{AH}\end{array}$ \\
\hline Net Trade & net trade balance & f.o.b.-c.i.f. (billions lira) & $\begin{array}{l}\text { OECD } \\
16765103\end{array}$ \\
\hline Cap Util & $\begin{array}{c}\text { rate of capacity } \\
\text { utilization }\end{array}$ & Business tendencies survey (\%) & $\begin{array}{l}\text { OECD } \\
163088 \mathrm{~F} 0\end{array}$ \\
\hline Hours Lost & hours lost & $\begin{array}{l}\text { time lost in labour } \\
\text { disputes ('000s hours) }\end{array}$ & $\begin{array}{l}\text { OECD } \\
16429880\end{array}$ \\
\hline$E m p$ & $\begin{array}{c}\text { seasonally adjusted } \\
\text { total employment }\end{array}$ & people (millions) & $\begin{array}{l}\text { OECD } \\
16426580\end{array}$ \\
\hline Net Trade/GDP & & $\frac{\text { Net Trade }}{\mathrm{P} \times \mathrm{GDP}}$ & \\
\hline Real $R$ & & $R / 400-\Delta p$ & \\
\hline
\end{tabular}

Note that for all variables lower case letters denote the natural logarithm of the upper case variable. The employment variable was seasonally adjusted by regression on seasonal dummy variables. 


\section{References}

Alogoskoufis, G., Bean, C. R., Bertola, G., Dolado, J., \& Saint-Paul, G. (1995). Unemployment: Choices for Europe, CEPR Monographs, Monitoring European Integration, Volume 5. Cambridge: Cambridge University Press.

Baici, E. (1992). Tasso di interesse e disoccupazione in italia. Ricerche applicate e modelli per la politica economica, Banca d'Italia.

Banerjee, A., Hendry, D. F., \& Mizon, G. E. (1996). The econometric analysis of economic policy. $O x$ ford Bulletin of Economics and Statistics, 58, 573-600. Special issue.

Bean, C. R. (1994a). European unemployment: A retrospective. European Economic Review, 38, 523534.

Bean, C. R. (1994b). European unemployment: A survey. Journal of Economic Literature, 32, 573-619.

Bertola, G., \& Ichino, A. (1995). Crossing the river: A comparative perspective on Italian unemployment dynamics. Economic Policy, 21, 359-420.

Binotti, A. M. (1994). The estimation of cointegrating vectors and the modelling of linear dynamic systems: an application to Italian wage data. mimeo, University of Pisa.

Blanchard, O. J., \& Summers, L. H. (1988). Beyond the natural rate hypothesis. American Economic Review, 78, 182-187.

Bontemps, C., \& Mizon, G. E. (1996). Congruence and encompassing. Economics Department, mimeo., European University Institute. Forthcoming in Stigum, B., ed., Studies in Economic Methodology, Cambridge, MA, MIT Press, 2001.

Campos, J., Ericsson, N. R., \& Hendry, D. F. (1996). Cointegration tests in the presence of structural breaks. Journal of Econometrics, 70, 187-220.

Chow, G. C. (1960). Tests of equality between sets of coefficients in two linear regressions. Econometrica, 28, 591-605.

Clements, M. P., \& Hendry, D. F. (1999). Forecasting Non-stationary Economic Time Series: The Zeuthen Lectures on Economic Forecasting. Cambridge, Mass.: MIT Press.

Clements, M. P., \& Mizon, G. E. (1991). Empirical analysis of macroeconomic time series: VAR and structural models. European Economic Review, 35, 887-932.

Daveri, F., \& Tabellini, G. (1997). Unemployment growth and taxation in industrial countries. Working paper no. 122, IGIER.

Doornik, J. A., \& Hendry, D. F. (1994). PcFiml 8: An Interactive Program for Modelling Econometric Systems. London: International Thomson Publishing.

Doornik, J. A., \& Hendry, D. F. (1997). Modelling Dynamic Systems Using PcFiml 9.10 for Windows. London: Timberlake Consulting. 
Doornik, J. A., Nielsen, B., \& Hendry, D. F. (1998). Inference in cointegrating models: UK M1 revisited. Journal of Economic Surveys, 12, 533-572.

Erickson, C. L., \& Ichino, A. (1994). Wage differentials in Italy: market forces, institutions, and inflation. In Freeman, R., \& Katz, L. (eds.), Differences and changes in wage structure. Chicago: Chicago University Press.

Fabiani, S., Locarno, A., Oneto, G., \& Sestito, P. (1996). Income policy and the NAIRU: Some lessons from the recent Italian experience. mimeo., Banca d'Italia.

Golinelli, R. (1997). Schemi teorici tradizionali e metodi econometrici moderni: una rivisitazione della curva di Phillips per l'Italia (1951-1996). mimeo, Universita di Bologna.

Hendry, D. F. (1995). Dynamic Econometrics. Oxford: Oxford University Press.

Hendry, D. F., \& Mizon, G. E. (1993). Evaluating dynamic econometric models by encompassing the VAR. In Phillips, P. C. B. (ed.), Models, Methods and Applications of Econometrics, pp. 272-300. Oxford: Basil Blackwell.

Hendry, D. F., \& Mizon, G. E. (1998). Exogeneity, causality, and co-breaking in economic policy analysis of a small econometric model of money in the UK. Empirical Economics, 23, 267-294.

Hendry, D. F., \& Mizon, G. E. (2000). On selecting policy analysis models by forecast accuracy. In Atkinson, A. B., Glennester, H., \& Stern, N. H. (eds.), Putting Economics to Work. Volume in Honour of Michio Morishima, pp. 71-119. London: London School of Economics. STICERD Occasional Paper No. 22 ISBN 0753013991.

Hendry, D. F., \& Neale, A. J. (1991). A Monte Carlo study of the effects of structural breaks on tests for unit roots. In Hackl, P., \& Westlund, A. H. (eds.), Economic Structural Change, Analysis and Forecasting, pp. 95-119. Berlin: Springer-Verlag.

Johansen, S. (1988). Statistical analysis of cointegration vectors. Journal of Economic Dynamics and Control, 12, 231-254.

Johansen, S. (1992). Determination of cointegration rank in the presence of a linear trend. Oxford Bulletin of Economics and Statistics, 54, 383-398.

Johansen, S. (1995). Likelihood-Based Inference in Cointegrated Vector Autoregressive Models. Oxford: Oxford University Press.

Layard, R., \& Nickell, S. J. (1985). The causes of British unemployment. National Institute Economic Review, 111, 62-85.

Marcellino, M. (1999). Some consequences of temporal aggregation for empirical analysis. Journal of Business and Economic Statistics, 17, 129-136.

Micali, A. (1990). La disoccupazione in Italia: livello e composizione interna. Economia e Lavoro, 24, 61-78.

Mizon, G. E. (1995). Progressive modelling of macroeconomic time series: the LSE methodology. In Hoover, K. D. (ed.), Macroeconometrics: Developments, Tensions and Prospects, pp. 107-169. Dordrecht: Kluwer Academic Press. 
Modigliani, F., Padoa Schioppa, F., \& Rossi, N. (1986). Aggregate unemployment in Italy 1960,1983. Economica, 53, 245-273.

Osterwald-Lenum, M. (1992). A note with quantiles of the asymptotic distribution of the ML cointegration rank test statistics. Oxford Bulletin of Economics and Statistics, 54, 461-472.

Perron, P. (1989). The Great Crash, the oil price shock and the unit root hypothesis. Econometrica, 57, $1361-1401$.

Rappoport, P., \& Reichlin, L. (1989). Segmented trends and non-stationary time series. Economic Journal, 99, 168-177.

Sargan, J. D. (1964). Wages and prices in the United Kingdom: A study in econometric methodology (with discussion). In Hart, P. E., Mills, G., \& Whitaker, J. K. (eds.), Econometric Analysis for National Economic Planning, Vol. 16 of Colston Papers, pp. 25-63. London: Butterworth Co. Reprinted as pp. 275-314 in Hendry D. F. and Wallis K. F. (eds.) (1984). Econometrics and Quantitative Economics. Oxford: Basil Blackwell, and as pp. 124-169 in Sargan J. D. (1988), Contributions to Econometrics, Vol. 1, Cambridge: Cambridge University Press.

Sestito, P. (1993). Determinazione del salario in italia: una rassegna della letteratura empirica. mimeo, Banca d'Italia. 